\title{
DYNAMIC MODEL MILLING MACHINE
}

\author{
Anton Panda \\ Technical university in Košice, Faculty of manufacturing technologies with the seat in \\ Prešov, Štúrova 31, 08001 Prešov, Slovakia, anton.panda@tuke.sk (corresponding author) \\ Volodymyr Nahornyi
}

Sumy State University, Faculty of Electronics and Information Technology, Section of Information Technology of Design, 2, Rymskogo-Korsakova st., 40007 Sumy, Ukraine, v.nahornyi@ cs.sumdu.edu.ua

\section{Jozef Mihok}

Technical University of Kosice, Faculty of Mechanical Engineering, Department of Industrial Engineering and Management, Nemcovej 32, 04200 Kosice, jozef.mihok@tuke.sk

\section{Iveta Pandová}

Technical university in Košice, Faculty of manufacturing technologies with the seat in Prešov, Štúrova 31, 08001 Prešov, Slovakia, iveta.pandova@tuke.sk

\section{Daniela Onofrejová}

Technical University of Kosice, Faculty of Mechanical Engineering, Department of Industrial Engineering and Management, Němcovej 32, 04200 Kosice, daniela.onofrejova@tuke.sk

Keywords: processing system, milling machine, tool wear, sound trend, predictive model

Abstract: The article describes the mathematical modelling results of the dynamics in order to determine the regularity of change in the model milling machine during the cutting tool wear. A close correlation between the sound trend accompanying the metalworking process and the roughness trend of the machined surface is shown. The calculation results serve as the basis for solving the problem of operational resource tool prediction. The tool wear operational forecast allows for the first time in the material processing history to put into practice an effective adaptive control technology of the cutting process, which determines the novelty of the material described in the article.

\section{Introduction}

The research purpose of the processing system dynamics is to study the regularity of its dynamic behaviour. Knowing these regularities allows you to purposefully manage the metalworking process and avoid the appearance of defects in the work piece.

These regularities appear [1] in:

- the trend and the spectral composition of the sound

- generated during the materials cutting processing;

- the trend of the roughness height parameter and its

- profile, which changes during the cutting process due

to tool wear.

These parameters have a decisive influence on the metalworking quality.

The mathematical description of the lathe elastic system must be connected with the processes occurring in the working area of the processing system [2-12].

Each adopted dynamic model uniquely corresponds to a certain differential equations system describing its behaviour. These equations can be considered as a dynamic system mathematical model. Depending on the type of differential equations, mathematical models can be linear and nonlinear [5].

In a linear dynamic model, the elastic forces are proportional to the deformations, the viscous resistance forces to the velocities, and the inertial forces to the accelerations. The article discusses a similar linear dynamic model milling machine.

\section{Methodology of modelling}

The research purpose was to establish dynamic behaviour regularity of the processing system during the technical condition (wear and destruction) of the cutting tool changes and the nature of this regularity in the amplitude sound wave trend accompanying the metalworking machines work.

The research subject was a typical technological metalworking system dynamic model - technological system of the milling machine.

The research technique consisted in:

- computer simulation of the processing system oscillations when changing due to cutting tool wear and destruction, its stiffness and damping characteristics;

- comparing the modelling results and verification experiments to confirm the calculations reliability and to identify regularity of changes manifestation in the dynamics of the processing system in the behaviour of the sound wave trend amplitude accompanying its work.

Dynamic model milling machine - the mass, stiffness and viscous coefficients of the simulated lathe nodes are indicated on the model diagram, respectively, using $m, k$

$\sim 1 \sim$ 
and $c$. These parameters characterize each simulated machine nodes partial oscillations in the direction perpendicular to the main axis for the simulated node axes of stiffness and damping. The generalized coordinate $\zeta_{i}$ describes the spatially oriented oscillations of the mass centre of each of the $i$-th modelled elements of the technological system.

Differential equations using the complex amplitude method by substitution $\xi(\tau)=\xi_{A} \cdot \exp (i \omega \tau)$, where $\xi_{A}$
- is the oscillation amplitude of the mass centre of the simulated machine element, $m$, were transformed into a algebraic equations system with complex coefficients. These algebraic equations system was solved by the Gauss method.

The model diagram is shown in Fig. 1, and its parameters - in Table 1. The oscillations of the model were described by means of six differential equations (1). In this case, the oscillations of the following elements of the technological

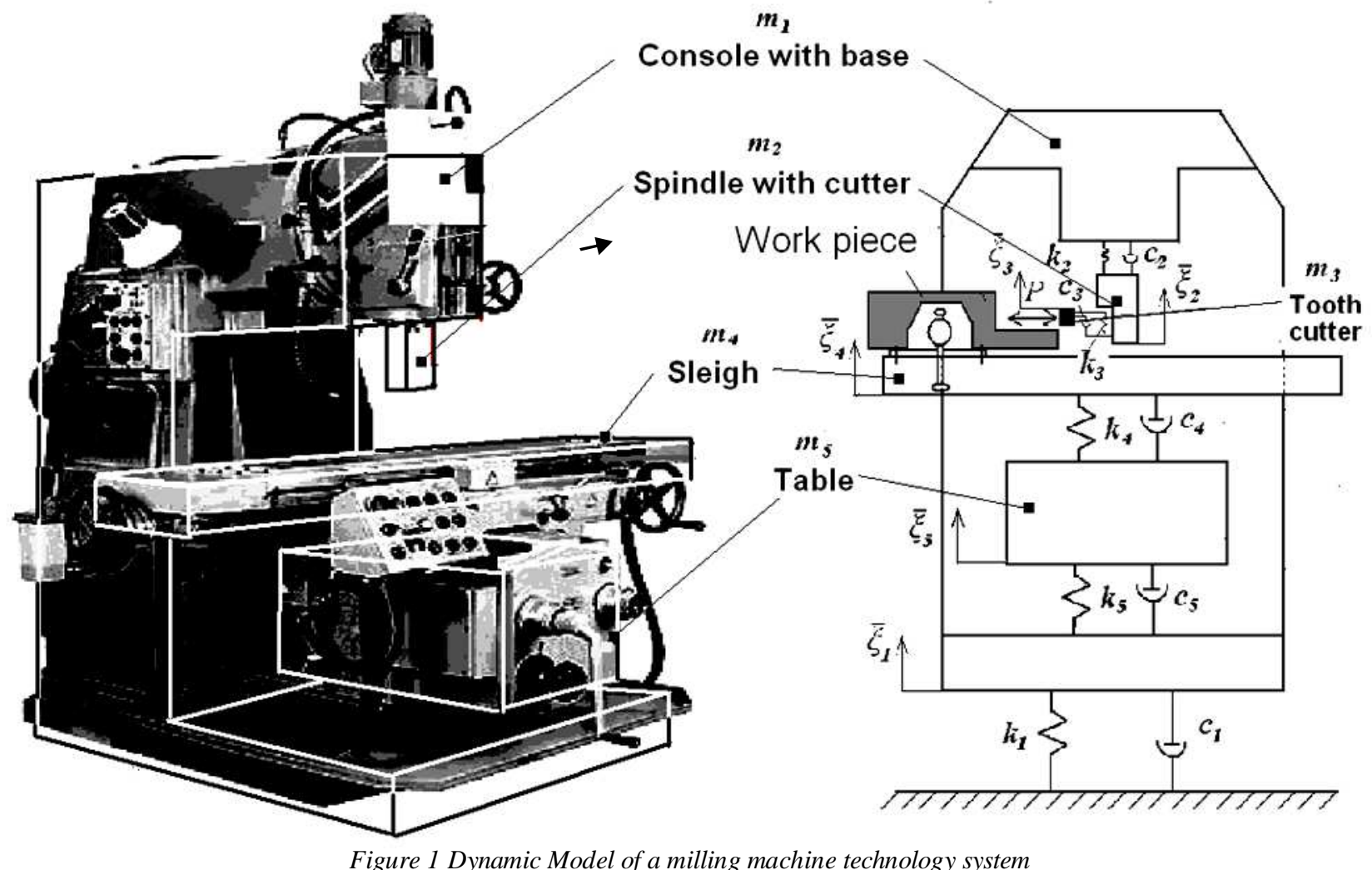

Figure 1 Dynamic Model of a milling machine technology system

Table 1 Dynamic model parameters of a milling machine

\begin{tabular}{|c|c|c|c|c|c|}
\hline \multirow[b]{2}{*}{ Dynamic parameter } & \multicolumn{5}{|c|}{$\begin{array}{l}\text { Simulated technological system node } \\
\text { (mass number) }\end{array}$} \\
\hline & $\begin{array}{c}\text { base console } \\
\text { (1) }\end{array}$ & $\begin{array}{l}\text { spindle with } \\
\text { chuck and } \\
\text { cutter } \\
\text { (2) }\end{array}$ & $\begin{array}{l}\text { tooth cutters } \\
\text { (3) }\end{array}$ & $\begin{array}{l}\text { slides } \\
(4)\end{array}$ & $\begin{array}{l}\text { table } \\
(5)\end{array}$ \\
\hline $\begin{array}{c}\text { Mass } \\
m_{\mathrm{i}}, k g\end{array}$ & 3494 & 17 & $0,3 \cdot 10^{-6}$ & 305 & 500 \\
\hline $\begin{array}{c}\text { Stiffness coefficient } \\
\mathrm{k}_{\mathrm{i}}, N / m \\
(f i, H z)\end{array}$ & $\begin{array}{l}8,6 \cdot 10^{9} \\
(250)\end{array}$ & $\begin{array}{l}8,1 \cdot 10^{6} \\
(110)\end{array}$ & $\begin{array}{c}1,9 \cdot 10^{8} \\
\left(4,14 \cdot 10^{6}\right)\end{array}$ & $\begin{array}{l}6,3 \cdot 10^{12} \\
(228)\end{array}$ & $\begin{array}{c}1,2 \cdot 10^{9} \\
(250)\end{array}$ \\
\hline $\begin{array}{l}\text { Viscous resistance } \\
\text { coefficient } \\
c, N / m / s e c \\
\text { (quality factor Q) }\end{array}$ & $\begin{array}{l}1,8 \cdot 10^{6} \\
(3)\end{array}$ & $\begin{array}{c}2348 \\
(17)\end{array}$ & $\begin{array}{l}0.5 \\
(10)\end{array}$ & $\begin{array}{l}1,4 \cdot 10^{5} \\
\quad(3)\end{array}$ & $\begin{array}{l}2,6 \cdot 10^{8} \\
(3)\end{array}$ \\
\hline
\end{tabular}

$\sim 2 \sim$ 
Note. Contact force $P_{C F}=107 \mathrm{~N}$; stiffness $k$ was determined by the following formula: $k_{i}=m_{i}\left(2 \pi f_{i}\right)^{2}$ , where $f i-i s$ the frequency of natural partial oscillations of the simulated node was calculated by the identification method; damping $c_{i}$ was determined by the following formula: $c_{i}=\frac{\sqrt{k_{i} \cdot m_{i}}}{Q_{i}}$, where $Q_{i}-$ is the quality factor (value) of the peak of the own partial oscillations of the modelled node was calculated by the identification method. System were considered: base console $\left(m_{1}, k_{1}, c_{1}\right)$; spindle with cutter $\left(m_{2}, k_{2}, c_{2}\right)$; tool blades

$\left(m_{3}, k_{3}, c_{3}\right)$; sleigh $\left(m_{4}, k_{4}, c_{4}\right)$; table and work piece $\left(m_{5}, k_{5}, c_{5}\right)$.

Differential equations:

$$
\begin{aligned}
& m_{1} \ddot{\zeta}_{1}+c_{1} \dot{\zeta}_{1}+k_{1} \zeta_{1}-c_{2}\left(\dot{\zeta}_{2}-\dot{\zeta}_{1}\right)-k_{2}\left(\zeta_{2}-\zeta_{1}\right)+c_{5}\left(\dot{\zeta}_{1}-\dot{\zeta}_{5}\right)+k_{5}\left(\zeta_{1}-\zeta_{5}\right)=0 ; \\
& m_{2} \ddot{\zeta}_{2}+c_{2}\left(\dot{\zeta}_{2}-\dot{\zeta}_{1}\right)+k_{2}\left(\zeta_{2}-\zeta_{1}\right)=0 ; \\
& m_{3} \ddot{\zeta}_{3}+c_{3}\left(\dot{\zeta}_{3}-\dot{\zeta}_{2}\right)+k_{2}\left(\zeta_{3}-\zeta_{2}\right)=-P(t) ; \\
& m_{4} \ddot{\zeta}_{4}+c_{4}\left(\dot{\zeta}_{4}-\dot{\zeta}_{5}\right)+k_{4}\left(\zeta_{4}-\zeta_{5}\right)=P(t) ; \\
& m_{5} \ddot{\xi}_{5}-c_{4}\left(\dot{\zeta}_{4}-\dot{\zeta}_{5}\right)-k_{4}\left(\zeta_{4}-\zeta_{5}\right)-c_{5}\left(\dot{\zeta}_{1}-\dot{\zeta}_{5}\right)-k_{5}\left(\zeta_{1}-\zeta_{5}\right)=0,
\end{aligned}
$$

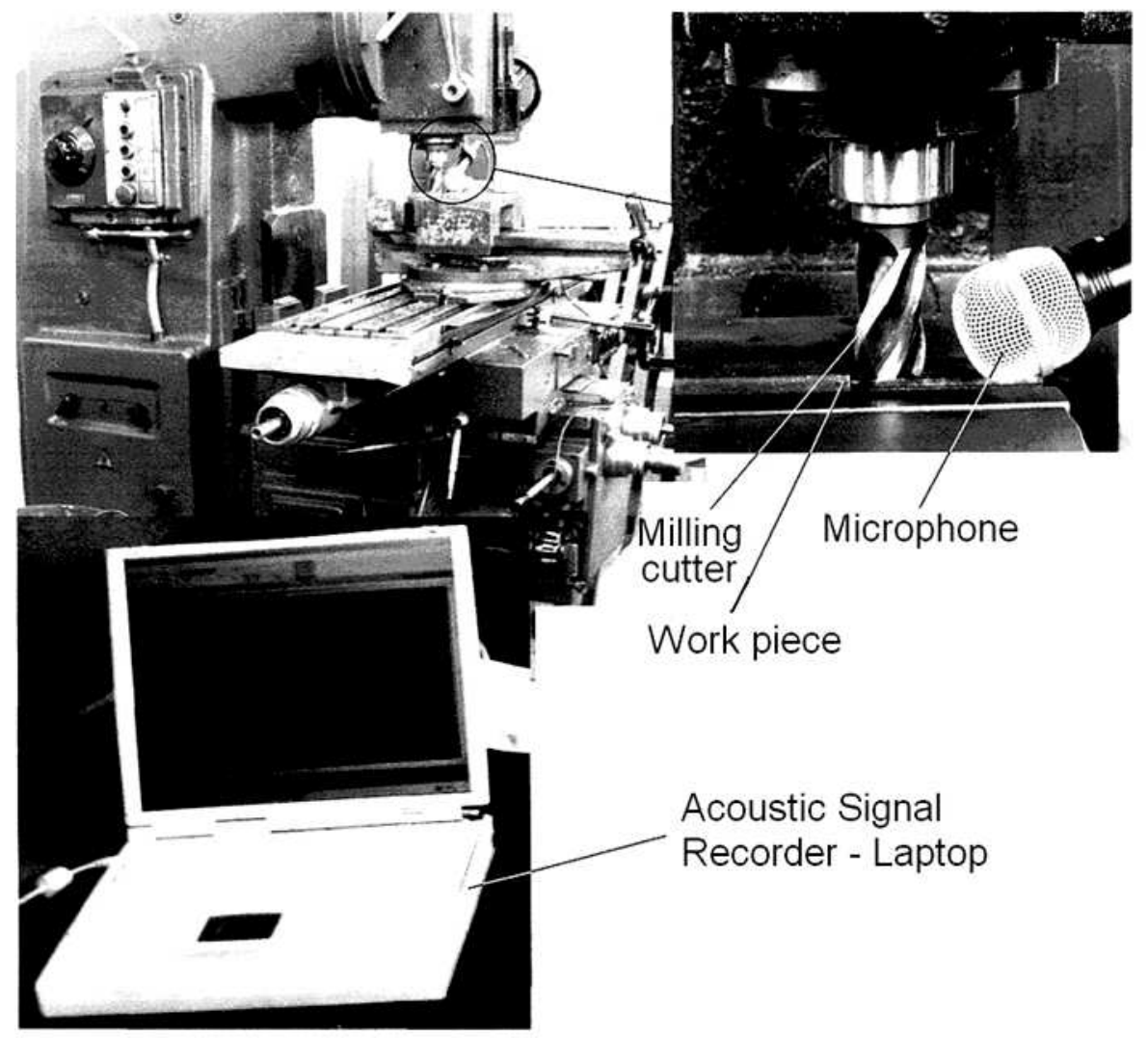

Figure 2 Placement the microphone near the cutting area

$$
\sim 3 \sim
$$

Copyright (C) Acta Simulatio, www.actasimulatio.eu

Algebraic equations:

$\left[\left(k_{1}+k_{2}+k_{5}-\omega^{2} m_{1}\right)+i \omega\left(c_{1}+c_{2}+c_{5}\right)\right] \zeta_{1}-\left(k_{2}+i \omega c_{2}\right) \zeta_{2}-\left(k_{5}+i \omega c_{5}\right) \zeta_{5}=0$;

$-\left(k_{2}+i \omega c_{2}\right) \zeta_{1}+\left[\left(k_{2}-\omega^{2} m_{2}\right)+i \omega c_{2}\right] \zeta_{2}=0$

$\left.\left[k_{2}+i \omega c_{2}\right] \zeta_{2}-\left[\left(k_{3 X}-\omega^{2} m_{2}\right)+i \omega c_{3 X}\right)\right] \zeta_{3}=-P(t, \omega)$

$\left[\left(k_{4}-\omega^{2} m_{4}\right)+i \omega c_{4}\right] \zeta_{4}-\left(k_{4}+i \omega c_{4 Z}\right) \zeta_{5}=P(t, \omega)$;

$-\left(k_{5}+i \omega c_{5}\right) \zeta_{1}-\left(k_{4}+i \omega c_{4}\right) \zeta_{4}+\left[\left(k_{5}+k_{4}-\omega^{2} m_{5}\right)+i \omega\left(c_{5}+c_{4}\right)\right] \zeta_{5}=0$;

\section{Results from experiments}

The sound was measured using a microphone placed near the cutting zone (Figure 2).

The results of experimental computational research are presented in Fig. 3 and Fig. 4. They are usually a comparison of calculated and experimental data. The calculation results are obtained when solving the equations system (2). The system solution was carried out repeatedly when changing the cutting time from 0 to $T$, equal to the period of durability (resource) tool with a time step $\Delta \tau=1$ sec. At the same time, at each time step, the frequency characteristics of the model oscillations were determined with successive changes in frequency from 0 to $2,500-3,000 \mathrm{~Hz}$ with a step in frequency $\Delta f=10$ $\mathrm{Hz}$. 
To assess the developed model reliability in the calculation in addition to the trend of the sound wave amplitude were investigated:

- the change nature over time of the sound implementation;

- sound trend generated during the cutting process;

- roughness profile;

- roughness profile trend.

The sound was measured using a microphone placed near the cutting zone (Figure 2).

Fig. 4a shows the actual and calculated sound spectra accompanying the cutting process, which visually coincide quite well with each other. This is also indicated by the quantitative degree assessment of their coincidence, described by their correlation coefficient, equal to 0.684 (Figure 3b). The most important are the

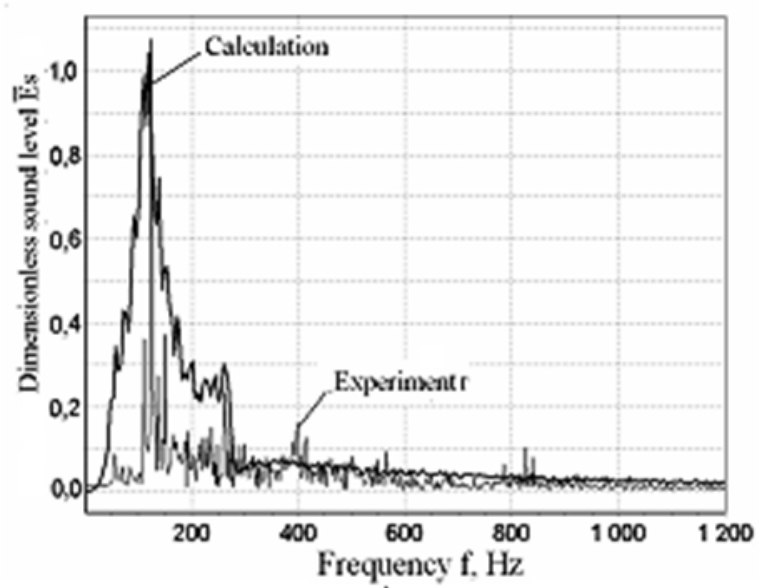

a)

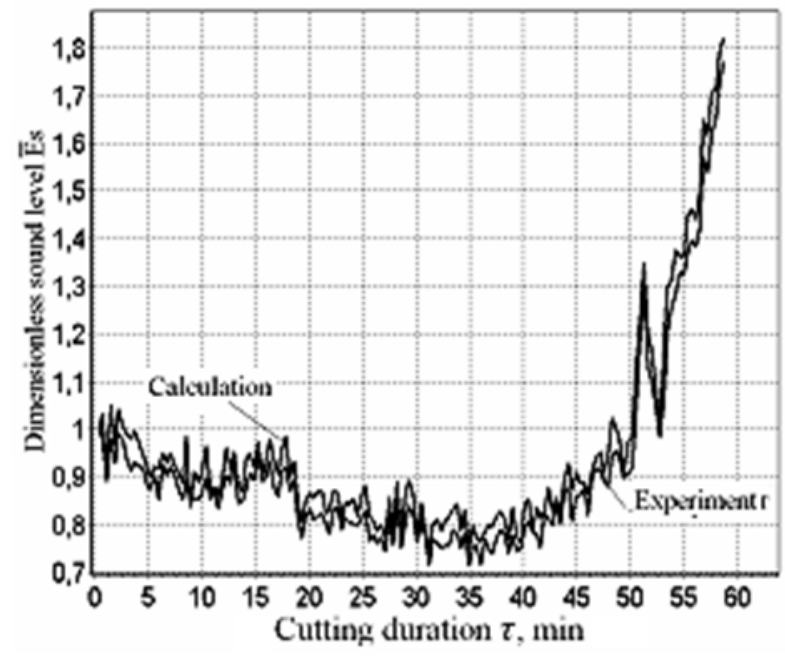

c) calculations describing the nature of the trend in sound $\bar{E}_{S}$ (Figure $3 c$ ) as the cutting blade wears. Correlation coefficient between calculated and experimental sound trend values $\bar{E}_{S}$ equals $R=0,993$ (Figure 3d). This information shows that the model reproduces well enough not only the frequency sound filling, but also describes the trend change nature of the sound over time as the instrument wears.

Fig. 4 shows the calculated trend of the altitude parameter $R a$ roughness and the roughness profile calculation.

At the same time, a fundamentally important result of calculations is the determination of the fact that sound trends $\bar{E}_{S}$ (Figure $3 c$ ) and roughness (Figure $3 a$ ) are identical.

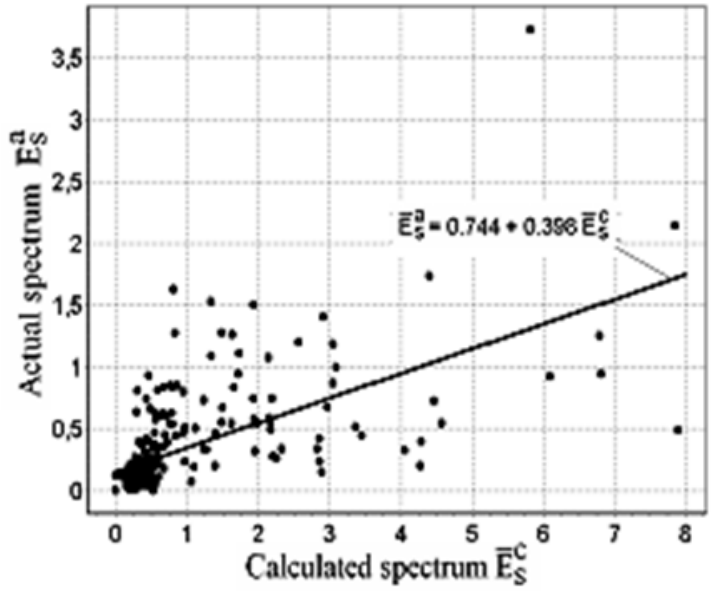

b)

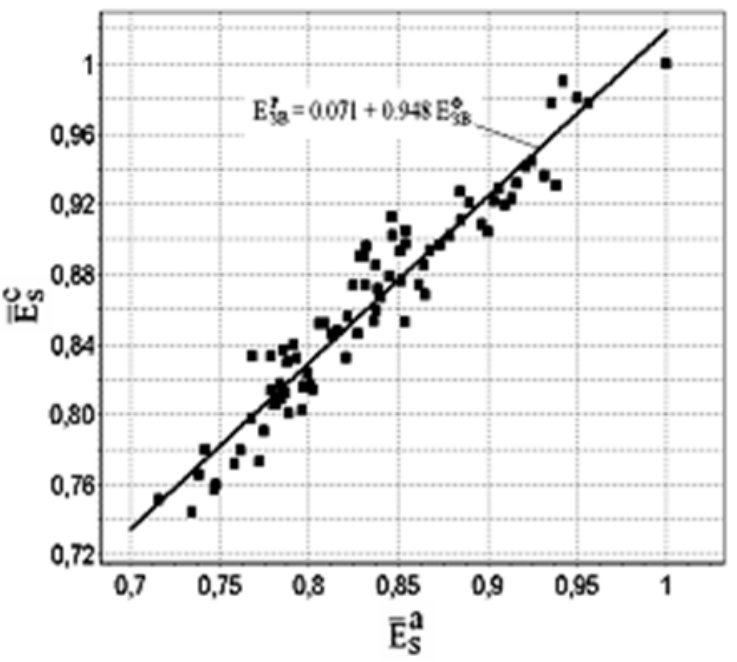

d)

Figure 3 Results of calculating the spectrum and trend of sound accompanying cutting processing: - comparison the calculated and actual sound spectra; $b$ - regression line between the actual and calculated spectra; $c$ ) comparing actual and calculated sound trends; d) regression line between actual and estimated sound trends 

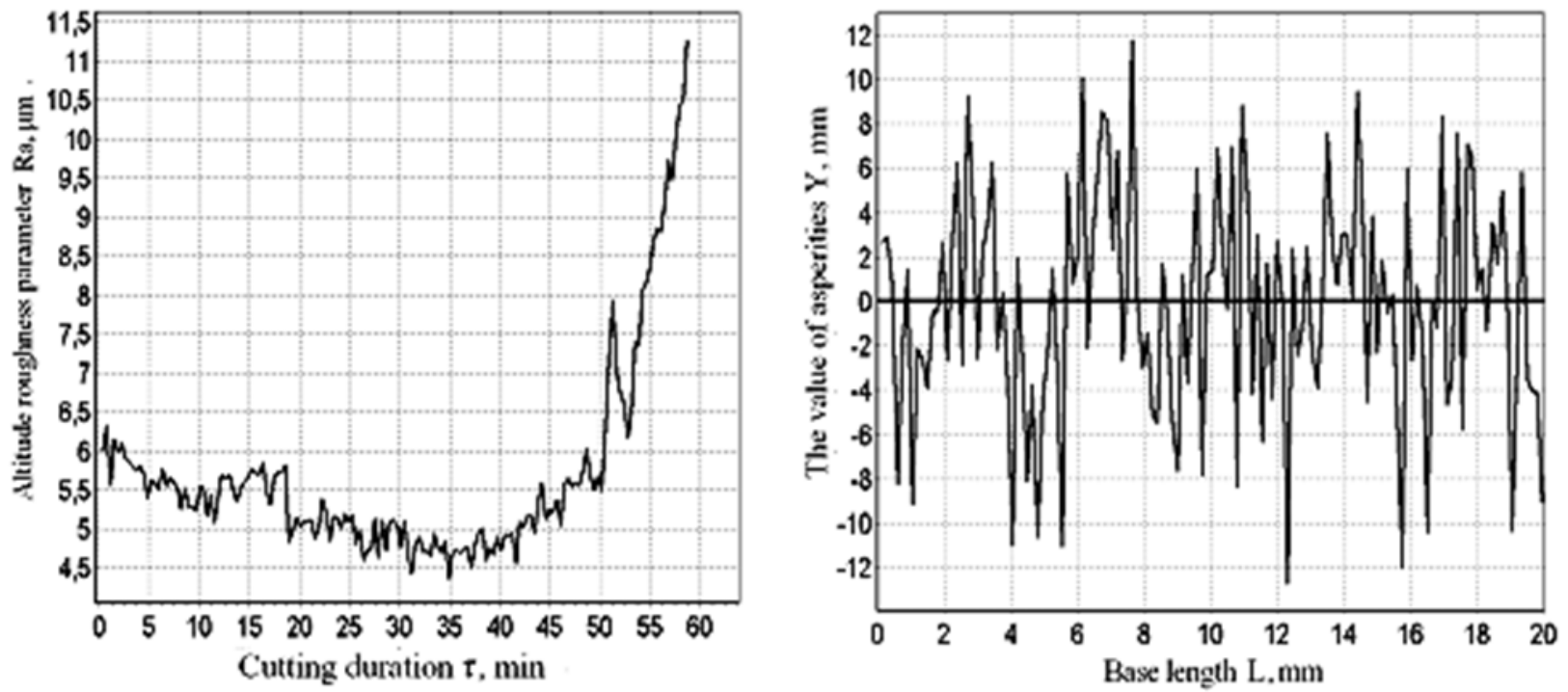

Figure 4 Roughness parameters obtained by the calculated method: $a$-is trend of altitude parameter roughness $R a ; b-i$ roughness profile $Y$

\section{Conclusion}

The mathematical modelling results of the dynamics of a milling machine serve as the basis for solving the problem of operational tool life prediction. This problem solution allows for the first time in the processing materials history to put into practice an effective technology of adaptive cutting process control.

To implement this technology, tool life prediction should be performed in real time directly during the processing of materials by cutting. In this case, the prediction technique should be based on the predictive model, which should be a time function and have a minimum of parameters, which must include the desired durability of the cutting tool $T$ as a numerical value.

\section{Acknowledgement}

The authors would like to thank the KEGA grant agency for supporting research work the project KEGA: 004TUKE-4/2017 "Implementation of research from mathematical modelling of microgeometry surface relation on consequential qualitatively parameters part produced with cutting machining into subjects of new study programme Technology of automotive production". This article was created by implementation of the grant project APVV-17-0258 "Digital engineering elements application in innovation and optimization of production flows".

\section{References}

[1] WEITS, V.L.: Forced oscillations in machine tools, M.: Mashgiz, pp. 288, 1959.

[2] DURKO, E.M.: Machine Tool Dynamics: A Manual, Ufa: USATU, pp. 92, 1996.

[3] ASHIKHMIN, V.N.: Introduction to mathematical modeling: a tutorial, M.: Logos, pp. 440, 2005.

[4] DEN-HARTOG, J.P.: Mechanical Oscillations, M.: State, publishing house physical, lit., pp. 580, 1960.

[5] AIKHOFF, P.: Fundamentals of identification of control systems, Estimation of parameters and status, M.: Mir, pp. 681, 1975.

[6] PATENT UA 91817 U UKRAINE, IPC G01N 3/58 (2006.01), Sposib itsinki znosu that istikosti lezovogo izalnogo instrumenta / Deposit VO, Nagorniy V.V.: The applicant and the master of patent Sumy State University. - № u 2014 03124; declare 03/27/14; publ. 07/10/14, Byul. No. 13.

[7] KREHEL, R., KOCISKO, M., POOR, P.: Technical Diagnostics in the Paper Industry, Proceedings of The $27^{\text {th }}$ International DAAAM Symposium 2016, 07750784. doi: 10.2507/27th.daaam.proceedings.112, 2016.

[8] BINASOVA, V., BUBENIK, P., DULINA, L., DURICA, L., EDL, M., KRAJCOVIC, M., MICIETA, B.: Delegate MASs for Coordination and Control of One-Directional AGV systems: A Proof-of-Concept, The International Journal of Advanced Manufacturing Technology, Vol. 94, No. 1-4, pp. 415-431, 2018.

[9] PATENT UA 92424 U UKRAINE, IPC B23B 25/00 (2014.01), Sposib appoinment of short-cut surfaces on parts with metal / Pledge V. O., Nagorniy V.V.: The applicant and the master of patent Sumy State University, - № u 2014 00000; declare 04/03/14; publ. 08/11/14, Bull. No. 15.

[10] PATENT UA 92987 U UKRAINE, IPC B23Q 11/02 


\section{DYNAMIC MODEL MILLING MACHINE}

Anton Panda; Volodymyr Nahornyi; Jozef Mihok; Iveta Pandová; Daniela Onofrejová

Attachment for control I will become the technological metal system and the/Pledge of V. O., Nagorniy V.V.: Applicant and patent master Sumy State University, - № u 2014 04238; declare 04/22/14; publ. 10.09.14, Byul. № 17.-8 p.

[11] FINDRIK BALOGOVÁ, A., PINDROCH, O., BODNÁROVÁ, S., FERANC, J., HUDÁK, R., ŽIVČÁK, J.: Determination of the geometrical and viscoelastic properties of scaffolds made by additive manufacturing using Bioplotter, Lékař a technika., Vol. 47, No. 3, pp. 88-95, 2017.

[12] TREBUŇA, P., PEKARČÍKOVÁ, M., KRONOVÁ, $\mathrm{J}$. : Automation of the casting process by the use of simulation software, Management and Production Engineering Review, Vol. 9, No. 1, pp. 82-89, 2018. 